\title{
Squamous Inclusion Cyst in the Palatine Tonsil Mimicking a Tumor
}

\author{
Vinson Louis Gonzaga Fernandes, Purva Khandolkar, Vivek G. Pillai, \\ Isha Rajendra Sukhthankar, Aditi Ashok Chari
}

Department of Otorhinolaryngology and Head \& Neck Surgery, Goa Medical College and Hospital, Bambolim, Goa, India

Email: fernandesvinson@yahoo.com

How to cite this paper: Fernandes, V.L.G., Khandolkar, P., Pillai, V.G., Sukhthankar, I.R. and Chari, A.A. (2018) Squamous Inclusion Cyst in the Palatine Tonsil Mimicking a Tumor. International Journal of Otolaryngology and Head \& Neck Surgery, 7, 249-253.

https://doi.org/10.4236/ijohns.2018.75026

Received: July 15, 2018

Accepted: August 14, 2018

Published: August 17, 2018

Copyright ( $) 2018$ by authors and Scientific Research Publishing Inc. This work is licensed under the Creative Commons Attribution International License (CC BY 4.0).

http://creativecommons.org/licenses/by/4.0/

\section{(c) (i) Open Access}

\begin{abstract}
Squamous inclusion cyst is a rare benign cystic lesion most commonly affecting the floor of mouth in the oral cavity. Its presence in the palatine tonsil of the oropharynx is an extremely rare occurrence. We highlight a case of an elderly female who was histopathologically diagnosed as squamous inclusion cyst of the palatine tonsil. We shall discuss the presentation, diagnosis, management and postoperative follow-up of the case.
\end{abstract}

\section{Keywords}

Squamous Inclusion Cyst, Palatine Tonsil, Benign

\section{Introduction}

Squamous inclusion cysts are benign lesions which can be developmental or acquired. Developmentally in the fetal period they are formed from abnormal squamous epithelial components of ectodermal tissue. They can also be acquired from trauma or surgery related implanted epithelium [1]. Squamous inclusion cysts have an incidence of $1.6 \%-7 \%$ in the head and neck region [2]. It can be congenital or acquired. Squamous inclusion cysts are synonymous with epidermoid cysts, epithelial cyst, keratinous cyst, sebaceous cyst, epidermal cyst, milia, epidermal inclusion cyst or the infundibular cyst [3]. Roser first gave the term epidermoid cyst in 1859 [4].

They commonly arise in the sublingual, submental, submandibular region, labial/lingual or buccal mucosa [2]. Involvement of the palatine tonsil is a rare occurrence. Histopathological examination is of utmost importance in every resected tonsil to differentiate benign squamous inclusion cysts from tonsillar squamous cell carcinomas. The objective of this case report is to throw light on a 
simple case of squamous inclusion cyst of the palatine tonsil and how it can mimic a tumor.

\section{Case Report}

A 59 years old female presented to our ENT outpatient department with history of noticing a mass on the left tonsil along with foreign body sensation in the throat since 1 month, which was insidious in onset and gradually progressive. She also had dry cough for a month. There was no associated pain or difficulty in swallowing. On examination bilateral tonsils were enlarged left side was grade 2 and right was grade 1 in size and not congested. There was a round yellowish cyst on the superior pole of the left palatine tonsil (Figure 1). It was smooth, soft to firm in consistency and did not bleed on touch. Neck examination revealed bilateral jugulo-digastric lymphadenitis, left more than right. Rest of the examination was unremarkable.

A working diagnosis of a tumoral mass on left tonsil under investigation was made. Blood investigations were normal. Patient was offered treatment in the form of an excisional biopsy of the tonsillar mass by undergoing a bilateral tonsillectomy.

Tonsillectomy was done along with excision of the left tonsillar tumor mass (Figure 2).

Specimen was sent for histopathological examination. Patient recovered well post operatively with no complications. Sections from histopathology revealed an epithelial squamous inclusion cyst along with chronic non-specific inflammation of the tonsil, suggestive of chronic tonsillitis (Figure 3).

Patient recovered well post operatively. She was followed up for 6 months and was symptom free with no recurrences. Overall prognosis was good. Patients consent was taken to publish this case report.

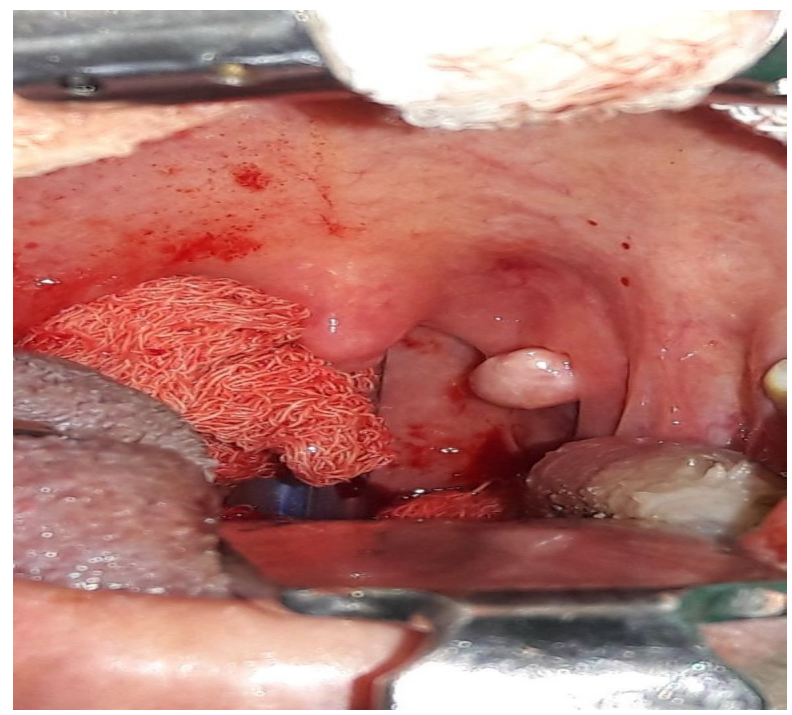

Figure 1. Clinical photograph showing a tumoral mass on the superior pole of the left palatine tonsil. 


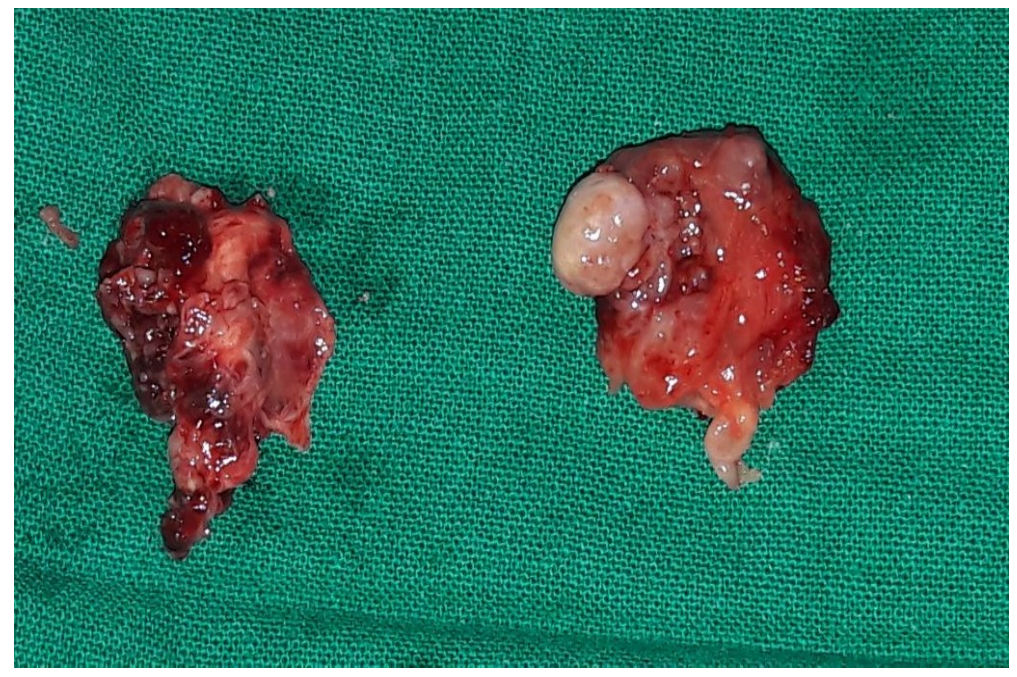

Figure 2. Clinical photograph of the post tonsillectomy specimen, the left tonsil with the tumor mass on its superior pole and the right tonsil.

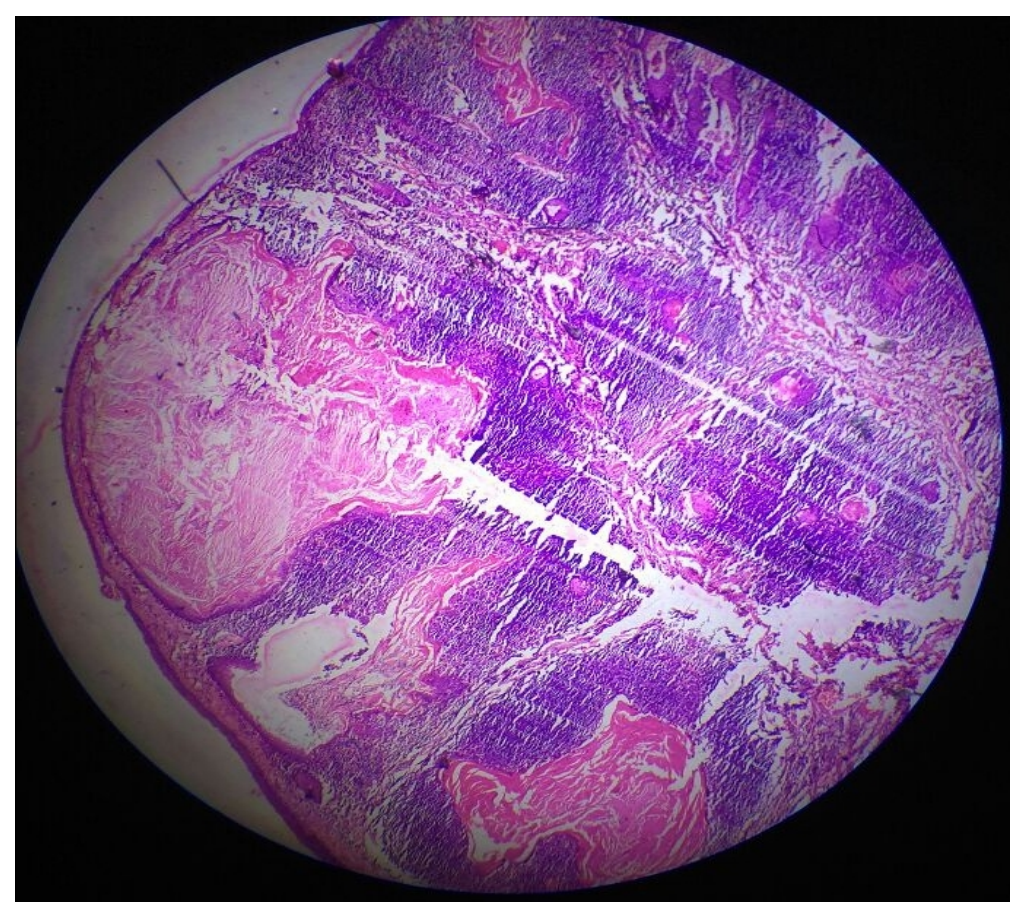

Figure 3. Photomicrograph showing a cyst lined by stratified squamous epithelium with keratinous material in the center. Lymphoid follicles with germinal centers were present in the wall of the cyst, suggestive of chronic tonsillitis (H \& E, 100×).

\section{Discussion}

The palatine tonsil is a lymphoid tissue present in the pharynx with an external lining of stratified squamous mucosa [5]. The cysts in oral cavity can be epidermoid, dermoid, teratoid [6]. Epidermoid cysts are enclosed and lined by stratified squamous epithelium only. Dermoid cysts contain skin, adnexal structures and teratoid cysts contain ecto, endo or mesodermal structures like muscle, bone, cartilage or fat. The treatment of choice is surgical excision. Recurrence 
after surgery is rare and malignant transformation into squamous cell carcinoma is reported but not common [7]. Squamous inclusion cyst is lined by simple squamous epithelium and its wall does not contain skin adnexal structures or fibrous elements [6]. Their etiology is varied, including hormonal influence during puberty to abnormal inclusion of cells during surgery/trauma or development from the epithelial remnants isolated during the closure of first and second branchial arches in the midline [8]. The male to female ratio with diagnosis of squamous inclusion cyst is 1:4 with majority in the age group of 10-35 years [6]. Our patient was a 59 year old female who presented with a mass in the left palatine tonsil. They usually present as an asymptomatic painless slow growing mass [9].

These cysts can be associated with certain hereditary syndromes like Gardner syndrome, basal cell nevus syndrome and pachyonychia congenita [8].

Diagnosis can be confirmed by fine needle aspiration (FNAC) or excisional biopsy [10]. The differential diagnosis of a squamous inclusion cyst are varied from benign lesions like dermoid cysts, lymphoepithelial cysts, hydatid cysts and squamous papilloma to tonsillar carcinoma [6]. Histopathologically we can easily differentiate these entities, hence gross and microscopic examination of every resected tonsillar mass is of utmost importance. Histopathology is the gold standard to rule out malignancy and to confirm the benign nature of tonsillar squamous inclusion cyst. Complications of squamous inclusion cysts are rare, but they include infection, scarring from removal and recurrence. Malignancies are very rare.

\section{Conclusion}

The importance of this rare case report is to highlight the rarity of squamous inclusion cyst of the palatine tonsil and the need for histopathological examination in each and every case of tonsillectomy, so as to differentiate between benign and malignant tumors.

\section{Conflicts of Interest}

The authors declare no conflicts of interest regarding the publication of this paper.

\section{References}

[1] Suga, K., Muramatsu, K., Uchiyama, T., Takano, N. and Shibahara, T. (2010) Congenital Epidermoid Cyst Arising in Soft Palate near Uvula: A Case Report. The Bulletin of Tokyo Dental College, 51, 207-211. https://doi.org/10.2209/tdcpublication.51.207

[2] Gulia, S.P., Lavanya M, Kamidi, V. and Arun Kumar SP (2015) Epidermoid Cyst of the Tonsil: An Incidental Finding. International Journal of Advances in Case Reports, 2, 777-779.

[3] Rajendran, R. (2009) Developmental Disturbances of Oral and Para Oral Structures. Shafers Textbook of Oral Pathology. 6th Edition, Elsevier Publication a Division of 
Reed Elsevier India Private Limited Noida (UP), 67-69.

[4] Shivakumar, M.S., Yogesh, T.L., Nagaraj, T. and Sinha, P. (2015) Epidermal Inclusion Cyst of Buccal Mucosa: A Rare Case Report. International Journal of Medical and Dental Case Reports, 2015, Article ID: 050115.

[5] Swarnagowri, B.N., Suba, G. and Prabhakaran, N. (2014) Epidermal Inclusion Cyst in Palatine Tonsil: A Case Report. Scholars Journal of Medical Case Reports, 2, 83-84.

[6] Erol, K., Erkan, K.M., Tolga, D. and Bengu, C. (2013) Epidermoid Cyst Localized in the Palatine Tonsil. Journal of Oral and Maxillofacial Pathology, 17, 148. https://doi.org/10.4103/0973-029X.110729

[7] Calderon, S. and Kaplan, I. (1993) Concomitant Sublingual and Submental Epidermoid Cysts: A Case Report. Journal of Oral and Maxillofacial Surgery, 51, 790-792. https://doi.org/10.1016/S0278-2391(10)80425-2

[8] Gnepp, D.R. (2009) Diagnostic Surgical Pathology of the Head and Neck. 2nd Edition, Elsevier, Philadelphia, 226-227.

[9] Tsirevelou, P., Papamanthos, M., Chlopsidis, P., Zourou, I. and Skoulakis, C. (2009) Epidermoid Cyst of the Floor of the Mouth: Two Case Reports. Cases Journal, 2, 9360. https://doi.org/10.1186/1757-1626-2-9360

[10] Dutta, M., Saha, J., Biswas, G., Chattopadhyay, S., Sen, I. and Sinha, R. (2013) Epidermoid Cysts in Head and Neck: Our Experiences, with Review of Literature. Indian Journal of Otolaryngology and Head \& Neck Surgery, 65, 14-21. 